\title{
Management of Liver Hemangioma Using Trans-Catheter Arterial Embolization
}

\author{
Kavous Firouznia ${ }^{1}$; Hossein Ghanaati ${ }^{1}$; Seyed Moayed Alavian ${ }^{2}$; Mohssen Nassiri Toosi ${ }^{3}$; \\ Nasser Ebrahimi Daryani ${ }^{3}$; Amir Hossein Jalali ${ }^{1}$; Madjid Shakiba ${ }^{1}$; Sima Hosseinverdi ${ }^{1,}$ \\ ${ }_{1}^{1}$ Advanced Diagnostic and Interventional Radiology Research Center (ADIR), Tehran University of Medical Sciences, Tehran, IR Iran \\ ${ }_{3}^{2}$ Baqiatallah Research Center for Gastroenterology and Liver Diseases, Tehran, IR Iran \\ ${ }^{3}$ Department of Gastroenterology Hepatology, Tehran University of Medical Sciences, Tehran, IR Iran \\ *Corresponding Author: Sima Hosseinverdi, Advanced Diagnostic and Interventional Radiology Research Center (ADIR), Tehran University of Medical Sciences, Tehran, IR Iran. Tel: \\ +98- 912 6825703, E-mail: simahosseinverdi@ymail.com
}

Received: December 3, 2014; Accepted: December 17, 2014

\begin{abstract}
Background: Hemangioma, a congenital vascular malformation, is the most common benign liver lesion that is usually remain stable subsequently requiring not treatment; however, complications such as abdominal pain or fullness, coagulation disturbances, and inflammatory syndrome may occur, demanding a specific treatment of hemangioma.

Objectives: To assess the safety, feasibility and efficacy of trans-catheter arterial embolization (TAE) for the treatment of Liver hemangioma Patients and Methods: TAE was performed on 20 patients with liver hemangioma. The embolic agent used was polyvinyl alcohol (PVA) particles (300-400 micron, Jonson and Johnson Cordis, USA). All patients were followed up for 6 months. Imaging was carried out and patients were also evaluated symptomatically through telephone interview by a physician.

Results: Twenty patients aged from 21 to 63 years (mean: 46.8, SD: 10.26) were included in this study. Post embolization syndrome, including abdominal pain, fever, and leukocytosis occurred in one patient 1 week after TAE and lasted for 3 days. No serious adverse event and TAE-related death was observed. None of the patient underwent another intervention including surgery. During follow up interval, decreased episode of abdominal pain was documented in all patients who had pain. Tumor enlargement was also stopped during the follow up. The average diameter of tumors was $97.00 \mathrm{~mm}$ (range: 25-200 SD: 47.85) and $88.95 \mathrm{~mm}$ (range: 23-195 SD: 43.27) before and after embolization, respectively. Comparison of images before and after TAE revealed statistically significant decrease in the size of lesion (P value: $0.004, \mathrm{t}: 3.31$ ).

Conclusions: Our findings indicate that TAE is a safe and efficient procedure for the treatment of liver hemangioma. Further studies with larger sample sizes are required to support therapeutic effects of TAE.
\end{abstract}

Keywords:Liver; Hemangioma; Patients

\section{Background}

Hemangioma, a congenital vascular malformation, is the most common benign liver lesion with the prevalence of $3 \%$ to $20 \%$, affecting females more than males. Liver hemangiomas usually are less than $5 \mathrm{~cm}$ in diameter and remain stable without any complications or malignant transformation subsequently no treatment is needed; however, complications comprising abdominal pain or fullness, coagulation disturbances, and inflammatory syndrome may occur $(1,2)$. In terms of diagnosis, hemangiomas have characteristic imaging features facilitating their diagnosis by modalities such as computed tomography (CT) scan, magnetic resonance imaging (MRI), and ultrasoungraphy (US) (2). Surgery is the first preferred option for treatment in case of need, including abdominal symptoms, complication such asKasabachMerritt syndrome, jaundice, rapid growth, uncertain diagnosis, and Bornman syndrome (3). Interventional radiologists have used less invasive therapeutic modali- ties not only for the treatment of hepatobilliary diseases but also for other organs (4-9). Among these less invasive procedures; radio frequency ablation, radiation therapy, and trans-catheter arterial embolization (TAE) have been used for hemangioma. Of note, surgical management is not always attainable and has more complications in comparison to the other less invasive options $(10,11)$. TAE primarily has been performed as a pretreatment to shrink the tumor leading to the decrease in complications during surgery (12). Recently, it has been used as a single procedure for patients with liver hemangioma.

\section{Objectives}

In the present study, we aimed to assess the safety, feasibility and efficacy of TAE for the treatment of hepatic hemangioma using a retrospective review of 20 patients.

Copyright (C) 2014, Kowsar Corp. This is an open-access article distributed under the terms of the Creative Commons Attribution-NonCommercial 4.0 International License (http://creativecommons.org/licenses/by-nc/4.0/) which permits copy and redistribute the material just in noncommercial usages, provided the original work is properly cited. 


\section{Patients and Methods}

The present study was conducted in the department of diagnostic radiology of Imam Khomeini complex affiliated with Tehran University of Medical sciences, Tehran, Iran, from April 2013 to Jun 2014. Data of patients, who had hepatic hemangioma that was treated by TAE, were retrospectively reviewed. This study was approved by the Ethical Committee of Tehran University of Medical Sciences. Methods and procedures and their risks were explained in full detail to patients and all patients signed written informed consent before intervention.The diag nosis of hepatic hemangioma was made by imaging studies, including computed tomography (CT) scan, magnetic resonance imaging (MRI), and ultrasonography (US). Radiological features of hemangioam during TAE procedure confirmed the diagnosis. Routine blood tests, liver and renal function tests were obtained from all subjects before and after procedure.

\subsection{TAE Procedure}

TAE was performed by an interventional radiologist through gaining percutaneous trans-arterial access to the hepatic arteryby puncturing the common femoral artery under the general anesthesia and hepatic artery was catheterized. The embolic agent used was polyvinyl alcohol (PVA) particles (300-400 micron, Jonson and Johnson Cordis, USA).

\subsection{Follow Up}

All patients were followed up for 6 months. Imaging was carried out 6 months after TAE. Patients were also evaluated symptomatically through telephone interview by a physician.

\subsection{Statistical Analysis}

Statistical analysis was performed using SPSS software version 17 for comparison of tumor size before and after TAE by paired t-test. P Value less than 0.05 was considered statistically significant. Descriptive statistics used for patient's characteristics expressed as mean and standard deviation (SD) for quantitative variables.

\section{Results}

Twenty patients aged from 21 to 63 years (mean: 46.8, SD: 10.26) were included in this study. Clinical characteristic of patients are summarized in Table 1. Female patient represented the dominant population of the study. A total of 25 lesions were diagnosed. Five patients had 2 lesions. Indications for TAE were abdominal pain $(n=15)$ and rapid tumor enlargement $(n=5)$. TAE was performed on 20 lesions. Imaging modalities used in follow up were US and CT scan in 17 and 3 patients, respectively (Figures 1 and 2 ). Post embolization syndrome, including abdominal pain, fever, and leukocytosis occurred in one female patient
1 week after TAE and lasted for 3 days and was conservatively treated and she recovered within 3 days. No serious adverse event and TAE-related death was observed. None of the patient underwent another intervention including surgery. During follow up interval, decreased episode of abdominal pain was documented in all patients who had pain. Tumor enlargement was also stopped during follow up time. The average diameter of lesions that underwent TAE was $97.00 \mathrm{~mm}$ (range: 25-200 SD: 47.85) and 88.95 mm (range: 23-195 SD: 43.27) before and after embolization, respectively. Comparison of images before and after TAE revealed statistically significant decrease in the size of lesion (P Value: 0.004, t:3.31).

\begin{tabular}{lc}
\hline Table 1. Clinical Characteristics of Patients \\
\hline \multicolumn{1}{l}{ Sex } & No. \\
\hline Female & 16 \\
\hline Male & 4 \\
\hline Number of lesions & 25 \\
\hline Location & \\
$\quad$ Right lobe & 17 \\
\hline Left lobe & 8 \\
\hline Number of giant hemangimas, $>\mathbf{1 0} \mathbf{~ c m ~}$ & 9 \\
\hline
\end{tabular}
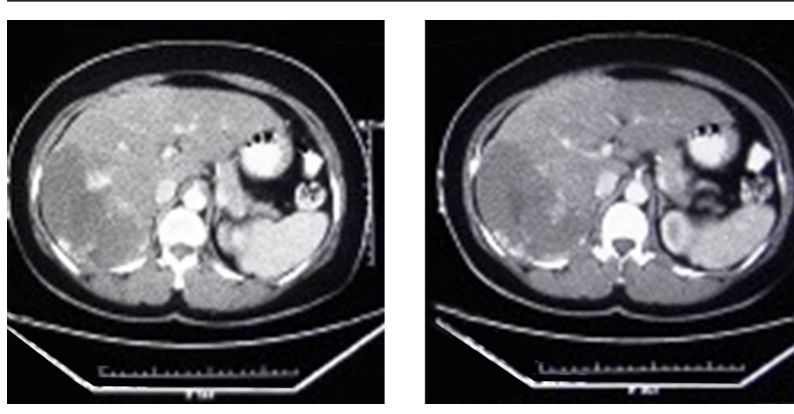

Figure 1. CT Scan Shows a Liver Hemangioma in a 52 Year-Old Female With Abdominal Pain

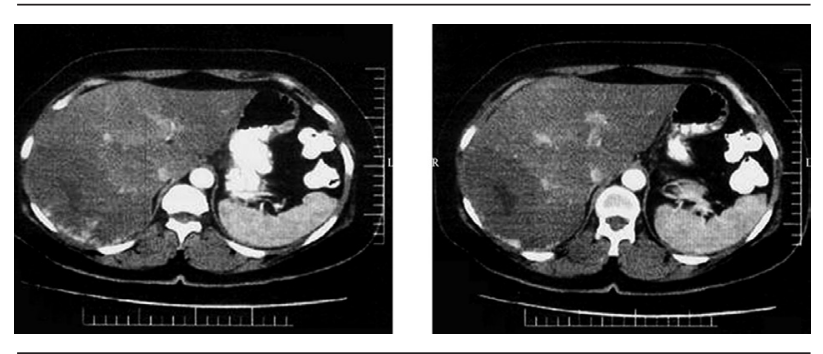

Figure 2. CT Scan of Liver After TAE

\section{Discussion}

Hepatic hemangiomas constitute the $70 \%$ of all benign liver tumors. The vast majority of these lesions are 
Firouznia Ket al.

found incidentally by imaging studies and remain asymptomatic, therefore no specific treatment is required $(1,13)$. Nevertheless, complications such as rupture, bleeding, Kasabach-Merritt syndrome, and organ or vessel compression are the main indications for treatment of hepatic hemangiomas (3). Abdominal pain is a common symptom in patients while it has been stated that this pain is mostly ascribed to other gastrointestinal diseases such as irritable bowel syndrome. Therefore we should consider other causes in case of persistence of pain after treatment of hemangioma $(14,15)$. With regard to the size of the tumor, giant hemangiomas defined as larger than $4 \mathrm{~cm}$ in most of the studies while some authors considered giant hemangiomas as larger than 10 $\mathrm{cm}$. According to the latter definition, giant tumors may contribute to produce events such as bleeding and rupture demanding a specific treatment. Of note, size of the tumor remains a controversial indication for therapy (3, 13). Surgical resection, preferably enucleation, is the first choice of treatment. Recently, other options have been applied for the treatment of hepatic hemangioma consisting of radiofrequency ablation, bevacizumab which is a monoclonal antibody, radiotherapy, chemotherapy, and TAE. Compared with aforementioned methods, surgery is a more invasive method and bears higher risks and longer term hospitalization $(10,11)$. Primarily, Yamamoto et al. have successfully performed TAE before surgical resection in a case of spontaneous rupture of a cavernous liver hemangioma (12). Accordingly, TAE was used as a method to shrink the tumor, particularly in giant hemangiomas, through blocking vascular reserve consequently leading to decreased hemorrhage during surgery (16). TAE has also been used effectively as a single therapy in recent studies in patients with hepatic hemangioma. However, there have been complications such as biliary tree damage (17), abscess formation, septicaemia, renal failure,bowel infarction,and post embolization syndrome (abdominal pain, nausea, fever, hypertension, thrombocytopenia, leukocytosis, and transient liver enzyme rise) (18). The preliminary goal of the present study was to ascertain the safety and feasibility of TAE. Our data showed that TAE is a safe and an attainable method for the treatment of hepatic hemangiomas. No major complication or any serious adverse event occurred during our study, except one patient who was a 28 year-old female that developed moderate post embolization syndrome. As a secondary goal, we aimed to assess the efficacy of TAE. In this regard, we compared follow up images with those taken before embolization as well as monitoring symptom relief in symptomatic patients. Our results showed that the size of tumors has been significantly decreased. In concerning of symptom relief, all patients who had abdominal pain or discomfort reported improvement or even some stated that the pain totally diminished. These outcomes are consistent with previous published studies (13, 19-25). Albeit, the great number of these studies have few sample sizes. In a study by Zeng et al. (24), 98 patients underwent TAE and followed up for 12 months. Imaging was done 6 and 12 months after TAE and compared with base line images revealing significant differences at both times. In contrast, Srivastava et al. (23) couldn't show any significant changes in the tumor size after TAE performed on 8 patients. Although our data showed statistically significant decrease in tumor size, but it may not seem clinically considerable.In conclusion, our findings indicate that TAE is a safe and efficient procedure for the treatment of hepatic hemangiomas. A major limitation of our study was that we didn't follow up patients for longer time, so further studies with larger sample sizes and long term follow up are required to support therapeutic effects of TAE.

\section{Authors' Contributions}

Study conceptand design: Hossein Ghanaati, Amir Hossein Jalai, Acquisition of data: Sima Hosseinverdi, Analysis and interpretation of data: Sima Hosseinverdi, Drafting of themanuscript: Sima Hosseinverdi, Critical revision of the manuscript for important intellectual content: Hossein Ghanaati, Seyed-Moayed Alavian, Mohssen Nassiri Toosi, Naser Ebrahimi Daryani, Kavous Firouznia, Statistical analysis: Sima Hosseinverdi, Madjid Shakiba, Administrative technical and material support: Madjid Shakiba Study supervision: Hossein Ghanaati.

\section{References}

1. Belghiti J, Cauchy F, Paradis V, Vilgrain V. Diagnosis and management of solid benign liver lesions. Nat Rev Gastroenterol Hepatol. 2014;11(12):737-49.

2. Venkatesh SK, Chandan V, Roberts LR. Liver masses: a clinical, radiologic, and pathologic perspective. Clin Gastroenterol Hepatol. 2014;12(9):1414-29.

3. Toro A, Mahfouz AE, Ardiri A, Malaguarnera M, Malaguarnera G, Loria $\mathrm{F}$, et al. What is changing in indications and treatment of hepatic hemangiomas. A review. Ann Hepatol. 2014;13(4):327-39.

4. Cakmakci E, Caliskan KC, Tabakci ON, Tahtabasi M, Karpat Z. Percutaneous liver biopsies guided with ultrasonography: a case series. Iran J Radiol. 2013;10(3):182-4.

5. Ghanaati H, Alavian SM, Jafarian A, Ebrahimi Daryani N, NassiriToosi $\mathrm{M}$, Jalali AH, et al. Imaging and Imaging-Guided Interventions in the Diagnosis and Management of Hepatocellular Carcinoma (HCC)-Review of Evidence. Iran J Radiol. 2012;9(4):167-77.

6. Ghanaati H, Firouznia K, Jalali AH, Shakiba M. How to Start Interventional Radiology. Iran Red Crescent Med J. 2013;15(12).

7. Caglayan B, Salepci B, Dogusoy I, Fidan A, Sener Comert S, Kiral N, et al. The role of convex probe endobronchial ultrasound guided transbronchial needle aspiration in the diagnosis of malignant mediastinal and hilar lymph nodes. Iran J Radiol. 2012;9(4):183-9.

8. Rajesh R, Dalip DS, Anupam J, Jaisiram A. Effectiveness of puncture-aspiration-injection-reaspiration in the treatment of hepatic hydatid cysts. Iran J Radiol. 2013;10(2):68-73.

9. Firouznia K, Ghanaati H, Sharafi A, Abahashemi F, Hashemi H, Jalali AH, et al. Comparing ovarian radiation doses in flat-panel and conventional angiography during uterine artery embolization: a randomized clinical trial. Iran J Radiol. 2013;10(3):111-5.

10. Lerner SM, Hiatt JR, Salamandra J, Chen PW, Farmer DG, Ghobrial RM, et al. Giant cavernous liver hemangiomas: effect of operative approach on outcome. Arch Surg. 2004;139(8):818-21.

11. Schnelldorfer T, Ware AL, Smoot R, Schleck CD, Harmsen WS, Nagorney DM. Management of giant hemangioma of the liver: resection versus observation. J Am Coll Surg. 2010;211(6):724-30. 
12. Yamamoto T, Kawarada Y, Yano T, Noguchi T, Mizumoto R. Spontaneous rupture of hemangioma of the liver: treatment with transcatheter hepatic arterial embolization. Am J Gastroenterol. 1991;86(11):1645-9.

13. Duxbury MS, Garden OJ. Giant haemangioma of the liver: observation or resection? Dig Surg. 2010;27(1):7-11.

14. Etemadi A, Golozar A, Ghassabian A, Zarei M, Hashemi Taheri AP Dawsey SM, et al. Cavernous hemangioma of the liver: factors affecting disease progression in general hepatology practice. Eur J Gastroenterol Hepatol. 2011;23(4):354-8.

15. Dumlu EG, Abbasoglu O, Hamaloglu E. Is surgical treatment of liver hemangiomas effective for pain relief? Chirurgia (Bucur). 2014;109(5):634-8.

16. Vassiou K, Rountas H, Liakou P, Arvanitis D, Fezoulidis I, Tepetes K. Embolization of a giant hepatic hemangioma prior to urgent liver resection. Case report and review of the literature. Cardiovasc Intervent Radiol. 2007;30(4):800-2.

17. Huang XQ, Huang ZQ, Duan WD, Zhou NX, Feng YQ. Severe biliary complications after hepatic artery embolization. World J Gastroenterol. 2002;8(1):119-23.

18. Allison DJ, Jordan H, Hennessy O. Therapeutic embolisation of the hepatic artery: a review of 75 procedures. Lancet. 1985;1(8429):595-9.

19. Malagari K, Alexopoulou E, Dourakis S, Kelekis A, Hatzimichail
K, Sissopoulos A, et al. Transarterial embolization of giant liver hemangiomas associated with Kasabach-Merritt syndrome: a case report. Acta Radiol. 2007;48(6):608-12.

20. Deutsch GS, Yeh KA, Bates WB, 3rd., Tannehill WB. Embolization for management of hepatic hemangiomas. Am Surg. 2001;67(2):159-64

21. Granov AM, Tarazov PG, Polysalov VN. [Arterial embolization in treatment of hepatic cavernous hemangioma]. Khirurgiia (Mosk). 1999(4):13-7.

22. Althaus S, Ashdown B, Coldwell D, Helton WS, Freeny PC. Transcatheter arterial embolization of two symptomatic giant cavernous hemangiomas of the liver. Cardiovasc Intervent Radiol. 1996;19(5):364-7.

23. Srivastava DN, Gandhi D, Seith A, Pande GK, Sahni P. Transcatheter arterial embolization in the treatment of symptomatic cavernous hemangiomas of the liver: a prospective study. Abdom Imaging. 2001;26(5):510-4.

24. Zeng Q, Li Y, Chen Y, Ouyang Y, He X, Zhang H. Gigantic cavernous hemangioma of the liver treated by intra-arterial embolization with pingyangmycin-lipiodol emulsion: a multi-center study. Cardiovasc Intervent Radiol. 2004;27(5):481-5.

25. Farges O, Daradkeh S, Bismuth H. Cavernous hemangiomas of the liver: are there any indications for resection? World J Surg. 1995;19(1):19-24. 